\title{
Grafik Tasarım Programı Öğrencilerinin Ders Başarı Düzeylerinin Mezun Oldukları Liselere Göre Değerlendirilmesi*
}

\section{Assessment of Graphic Design Program Students' Course Achievement Levels in Terms of Their High School Graduation}

\author{
Mehmet Taragay Ayçe, ${ }^{a}$ Orhan Sevindik ${ }^{b, * *}$ \\ a Öğr. Gör. Dr., İstanbul Arel Üniversitesi, Meslek Yüksekokulu, 34295, İstanbul/Türkiye. \\ ORCID: 0000-0002-6539-8182 \\ b Dr. Öğr. Üyesi, İstanbul Üniversitesi, Teknik Bilimler Meslek Yüksekokulu, 34452, İstanbul/Türkiye. \\ ORCID: 0000-0001-6162-7016
}

\section{MAKALE BİLGİSI}

\section{Makale Geçmişi:}

Başvuru tarihi: 14 Kasım 2016

Düzeltme tarihi: 29 Eylül 2017

Kabul tarihi: 16 Ekim 2017

\section{Anahtar Kelimeler:}

Başarı Düzeyi

Meslek Lisesi

Genel Lise

Grafik Tasarım Programı

\section{ARTICLE INFO}

\section{Article history:}

Received 14 November 2016

Received in revised form 29 September 2017 Accepted 16 October 2017

\section{Keywords:}

The Level of Success

Vocational High School

High School

Graphic Design

\section{ÖZ}

Bu çalışmada meslek yüksekokulu Grafik Tasarım programı öğrencilerinin bölüm derslerindeki başarı düzeyleri, mezun oldukları lise türleri göz önüne alınarak incelenmiştir. Çalışma, İstanbul Arel Üniversitesi Meslek Yüksekokulu Grafik Tasarım programı öğrencileri temel alınarak yapılmıştır. Yöntem olarak ögrenciler, mezun oldukları liselere göre gruplandırılmış ve üniversite eğitimlerinde seçilen derslere göre başarı durumları incelenmiştir. Veriler, çeşitli istatistik yöntemleri kullanılarak analiz edilmiştir. Grafik Tasarım programındaki dersler incelendiğinde mezun olunan derslere göre başarı düzeylerinin değişkenlik gösterdiği görülmüştür.

\section{Giriş}

Meslek yüksekokullarının doğuşu, mavi yaka çalışan ile beyaz yaka çalışan arasındaki iletişimi etkin bir şekilde sağlayacak personele ihtiyaç duyulması ile olmuştur. Ara eleman olarak tabir edilen meslek yüksekokulu (MYO) mezunları, işçi ile üst düzey yönetici arasında iletişimin aktif halde yürütülmesini sağlayan bir dönüştürücüdür.

Tarihi perspektiften bakıldığında önlisans düzeyindeki eğitimin, kitleselleşen insan topluluklarının ihtiyaç duyduğu eğitimi almaları sağlamak üzere ortaya çıktığını söylemek mümkündür (Karasar, 1981: 23). Önlisans uygulamalarının

\footnotetext{
* Bu çalışma, 04-05 Kasım 2016 tarihlerinde İstanbul'da düzenlenen 5. Uluslararası Matbaa Teknolojileri Sempozyumu'nda bildiri olarak sunulmuştur.

** Sorumlu yazar/Corresponding author.

e-posta: orhansevindik@istanbul.edu.tr
} 
yayınlaşması ise II. Dünya savaşı sonrasında üretimde ortaya çıkan eleman ihtiyacının en yüksek seviyesine ulaşması ile olmuştur. Fabrikaların ihtiyaç duyduğu elemanın hızlı bir şekilde yetiştirilerek üretime dâhil edilmesi, önlisansları önemli hale getirmiştir (Vardar, 1971: 12; Bahşi, 2011: 168).

Türkiye'de önlisans programları, kuruldukları günden bugüne, pek çok değişim yaşamış ve birbirinden farklı pek çok kurumun altında faaliyet göstermiştir (Kavak, 1998: 103-106; Odabaş1, 2013: 270). En son değişim ise 1982 yılında yürürlüğe giren Yüksek Öğretim Kanunu ile olmuştur. Önlisans uygulamaları ilgili Kanunla birlikte üniversitelerin çatısı altına girmiştir (Bedük, 1996: 91; Balcı, 1995a: 2; Balc1, 1995b: 14).

Mesleki ve Teknik Eğitim Bölgesi (METEB) Projesi ile birlikte mesleki ve teknik lise mezunlarının önlisans programlarına sınavsız geçiş yapabilme hakkı verilmiştir. Ancak uygulama eğitimin istenilen kalitede olmasını olumsuz etkileyerek beraberinde bir dizi probleme yol açtığı görülmektedir (YÖK, 2006a; YÖK, 2006b). Bir taraftan uygulamanın sonuçları tartışılırken, diğer taraftan, mesleki ve teknik ortaöğretim kurumlarına olan ilginin azalması, düz lise çıkışlı mezunların da önlisans programlarını kazanarak ilgili programlara gelmelerine yol açmıştır. Sınıflarda homojen olmayan bir görüntünün var olması, verilen derslerin verimini de çeşitli düzeylerde etkilediği düşünülmektedir (Özdemir, 2009: 96; Tunç, 2005: 77; Nargün ve Yüksel, 2009: 190-191; Henden, 2006: 158-159).

Grafik tasarımın, plastik sanatlar içinde bulunduğu konum itibariyle, işlevsel olarak diğer sanat dallarına göre farklı bir konumu vardır. Çünkü soyut bir yapısı olmasına rağmen ortaya çıkardığı ürünlerin ekonomik boyutunun var oluşu grafik tasarımı plastik sanatlardan ayrıştırır (Becer, 1993: 47; Drucker ve McVarish, 2013: 7). Ayrica, grafik tasarım uygulamaları sonucunda ortaya çıkan ürünlerin çeşitli yöntemler (baskı) kullanılarak çoğaltılabiliyor olması, grafik tasarımı kitle iletişiminin merkezinde önemli bir konuma yerleştirir (Tepecik, 1998: 67). Grafik tasarımın ana gayesi, insanların anlık bakışlarını ürünün üzerine çekerek, akılda kalıcı olmayı başarmaktır. Böylece, grafik tasarım, ürettiği her türlü ürün ile çağımızın en önemli konusu olan pazarlama ve satış ikilisinin işlemesindeki bir dişli haline gelerek istenilen amaca ulaşmaya katkı vermiş olur (Mercin ve Alakuş, 2009: 173-174).

Alan ile ilgili araştırmalar yürüten bilim insanları grafik tasarımın tarihini insanların mağara duvarlarına yaptıkları çizimlere kadar götürseler de, aslında grafik tasarım bir 20. Yüzyıl fenomeni olarak karşımızda durur (Ertosun, 2006: 5). Çünkü onu gerçekten var eden en önemli olgular son yüzyılda karşımıza çıkmıştır. Matbaanın gelişimi ve fonksiyonel hale gelişi, resimle sanatçının ortaya koyduğu biricik ürünün çoğaltılmasına olanak sağlaması, resmin içinden çıkan ama resimden tamamen farklı kurallara sahip olan bir dal olan grafik tasarımın doğmasına sebep olmuştur. Grafik tasarımın gerçek anlamda doğuşunu etkileyen bir diğer faktör ise; sanayileşmenin getirdiği büyük ve kalabalık kentlerdeki insanların artık birer kitle olarak algılanması ve bu kitlelere kısa yoldan ulaşarak onları manipüle edilmesinin zorunluluğudur (Sürmeli, 2013: 101-105).

19. Yüzyılın sonlarında ortaya çıkan çeşitli sanat hareketleri (Art and Crafts/Sanat ve El Emeği, Art Nouveau/Yeni Sanat ve Bauhaus Ekolü) grafik tasarımın gelişmesine yol açarak, kendine özgü bir yapıya kavuşmasına olanak tanımıştır (Çakır, 2014: 21-26; Sözen ve Tanyeli, 1992: 78; Becer, 1999: 76; Tansağ, 1993: 256; Lynton, 2004: 158; Gombrich, 1980: 46). 20. Yüzyıla damgasını vuran 2. Dünya Savaşı ve ardından ortaya çıkan Amerikan hegemonyası, grafik tasarımında da Amerikan tarzının doğmasına yol açmıştır (Bektaş, 1992: 22; Becer, 1999: 277; Çakır, 2015: 27-28; Sürmeli, 2013, 102).

Cumhuriyet öncesi dönemdeki sanat ve grafik tasarım eğitim için dönüm noktası Sanayi-i Nefise Mektebi'nin kuruluşu olarak görülebilir. 1 Ocak 1882 yılında Paris Güzel Sanatlar Okulu/L'ecole Des Beaux okulu örnek alınarak kurulan okulda yer alan dört şubeden birisi Sanayi-i Tezyiniye şubesi olmuştur. Sanayi-i Tezyiniye şubesinde öğrenciler grafik tasarım temelli olan dersleri (nakş-1 tezyini, tezyinat-1 dahiliye, resm-i tezyini-i sınai ve freks ve pano) almışlardır. (MSGSÜ, 2011: 14-15). Günümüzde ise grafik tasarım eğitimi, ortaöğretim, önlisans, lisans, ve lisansüstü düzeylerde kendine yer bulmuştur (Sevindik, 2016: 43-45).

Önlisans düzeyindeki grafik tasarım eğitimi 'Grafik Tasarım Programı' adı ile Tasarım Bölümü altında eğitim ve öğretim faaliyetlerine devam etmektedir. Tasarım Bölümü ise Uluslararası Eğitimi Sinıflandırma Standardı'na (International Standard Classification of Education - ISCED) göre, 21 Sanat eğitim ve öğretim temel alanı içinde yer almaktadır (YÖK, 2011: 2-4). Grafik tasarım programlarındaki eğitim, teorik ve uygulama olmak üzere iki eksen üzerinde ilerlemektedir. Teorik düzeyde sanat ve çoğaltma (bask1) süreçleri anlatılırken, uygulama boyutunda ağırlıklı olarak paket programların kullanımı yer almaktadır.

Önlisans düzeyinde grafik tasarım eğitimlerine 1982 yılında yürürlüğe giren 2547 sayılı Kanun çerçevesinde yeniden şekillendirilen üniversitelerin bünyesinde rastlanmaktadır. Önlisans düzeyindeki ilk grafik tasarım eğitim 1982 yılında 4 üniversite bünyesindeki meslek yüksekokullarında başlamıştır. Günümüzde ise 36'sı devlet, 20'si vakıf ve 5'i vakıf MYO olmak üzere toplamda 61 üniversite bünyesinde önlisans grafik tasarım programı bulunmaktadır (YÖK, 2016).

\section{Yöntem}

\subsection{Araştırmanın Amacı ve Kapsamı}

Araştırma;

(i) Grafik Tasarım Programı (GTP) mezunlarının, geldikleri lise türünün, aldıkları önlisans eğitimindeki başarı durumuna etkisinin olup olmadığını;

(ii) Mezunların, aldıkları teorik ve uygulamalı derslerin birbirlerinin üzerinde etkisinin olup olmadığını;

(iii) Grafik Tasarım Programı mezunlarının, öğrenim türünün (örgün ve II. Öğretim) mezuniyet not ortalaması üzerinde etkisinin olup olmadığını tespit etmeyi amaçlar.

Araştırmanın kapsamı ise; İstanbul Arel Üniversitesi Meslek Yüksekokulu Grafik Tasarım Programı mezunlarının tamamıdır. 


\subsection{Araştırmada Kullanılan Yöntem}

Araştırma kapsamında SPSS paket programı kullanılarak, mezunların verileri Ki-Kare bağımsızlık testi üzerinden değerlendirilmiştir. Ki-Kare bağımsızlık testi; iki ya da daha fazla birbirinden bağımsız değişken grup arasında ilişki olup olmadığını tespit etmek üzere kullanılmaktadır (Durmuş vd., 2013: 72). Ki-Kare bağımsızlık testinin uygulanabilmesi için gözlem sonuçları gruplandırılarak birleşik seriler oluşturulmuştur.

\subsection{Araştırmanın Hipotezleri}

Araştırma kapsamında aşağıdaki alternatif hipotezler geliştirilmiş̧ir. Yapılan Ki-Kare testi analizi sonuçlarına göre alternatif hipotezler kabul ya da reddedilmiştir. Alternatif hipotezler üç ana grup altında toplanmıştır.

(i) Grafik Tasarım Programı mezunlarının, geldikleri lise türlerinin önlisans programında aldıkları derslerdeki başarısına etkisini inceleyen hipotezler;

- H1: Mezun olunan lise, Grafik Tasarım Programı mezuniyet derecesini etkilemektedir.

- H2: Mezun olunan lisenin, Grafik Tasarım Programındaki uygulamalı dersler üzerinde etkisi vardir.

H3: Mezun olunan lisenin, Grafik Tasarım Programındaki teorik dersler üzerinde etkisi vardir.

(ii) Grafik Tasarım Programı mezunlarının aldıkları uygulamalı dersler (Grafik Tasarım I, II, III ve IV dersleri) ile teorik derslerin (Bask1 Teknikleri ve Sanat Tarihi) birbirleri üzerinde etkisinin olup olmadığını inceleyen hipotezler;

- H4: Sanat Tarihi dersindeki başarının, uygulamalı derslerin (Grafik Tasarım I, II, III ve IV dersleri) başarısı üzerinde etkisi vardır.

- H5: Baskı Teknikleri dersindeki başarının, uygulamalı derslerin (Grafik Tasarım I, II, III ve IV dersleri) başarısı üzerinde etkisi vardır.

(iii) Öğrenim türünün (Örgün ve ikinci öğretim) derslerdeki (uygulamalı ve teorik) başarının ve mezuniyet not ortalamasina etkisini inceleyen hipotezler;

H6: Öğrenim türünün (Örgün ve ikinci öğretim), uygulamalı derslerdeki başarı üzerinde etkisi vardir.

- H7: Öğrenin türünün (Örgün ve ikinci öğretim), teorik derslerdeki başarı üzerinde etkisi vardır.

- H8: Öğrenim türünün (Örgün ve ikinci öğretim), mezuniyet not ortalaması üzerindeki etkisi vardır.

\section{Bulgular}

Araştırma kapsamında değerlendirmeye alınan 477 Grafik Tasarım programı mezununun geldikleri lise türleri dört gruba ayrılmıştır. Bunlar sırasıyla; Endüstri Meslek Lisesi, Meslek Lisesi, Kız Meslek Lisesi ve genel lisedir. Ayrıca önlisans mezuniyet notu ise 4 gruba bölünmüştür. Alternatif hipotez kapsamında mezun olunan lisenin, Grafik Tasarım programındaki mezuniyet derecesi üzerindeki etkisinin olup olmadığına dair bulgular, Tablo 1'de yer almaktadır.
Tablo 1 incelendiğinde; Grafik Tasarım programını en çok $(\% 38,4)$ tercih edenlerin düz lise mezunu oldukları görülmektedir. İkinci sırada ise Kız Meslek Lisesi $(\% 25,6)$ yer almaktadır. Önlisans mezuniyet not aralığının ise daha çok 2,00 ile 3,00 not aralı̆̆ında yoğunlaştığı $\quad(\% 70)$ görülmektedir. En düşük aralık ise 3,51 ile 4,00 mezuniyet not aralığı $(\% 8,8)$ olmuştur. En başarılı lise türü, Meslek Lisesi $(\% 12,2)$ olurken, başarı oranı en düşük lise türü ise Endüstri Meslek Lisesi $(\% 5,3)$ olmuştur. İlgili alternatif hipotez (H1) kapsamında yapılan Ki-Kare testi sonuçlarına göre; $\mathrm{P}<0,05 \quad(0,000)$ olarak bulunmuştur. Dolayısıyla alternatif hipotez $(\mathrm{H} 1)$ kabul edilerek $\mathrm{H} 0$ reddedilmiştir. Gelinen lisenin, önlisans Grafik Tasarım programındaki mezuniyet notunu etkilediği sonucunu ortaya çıkarmıştır.

Mezun olunan lise türüne göre; Grafik Tasarım Programı mezunlarının uygulamalı derslerdeki başarı durumunu değerlendirilmiştir. Değerlendirmede; GTP müfredatının dört dönem de yer alan Grafik Tasarım dersleri kullanılmıştır. Mezun olunan lisenin, GTP eğitimi sırasında alınan uygulamalı dersler üzerindeki etkisini değerlendiren Tablo 2'de yer almaktadır.

Tablo 2 incelendiğinde; GTP mezunlarının geldikleri lise türüne değerlendirmesinde, Kız Meslek $(27$ Kişi - \%22,1) ve Meslek Lisesi (23 Kişi - \%20,0) mezunlarının GTP uygulamalı derslerde daha başarılı oldukları görülmektedir. Uygulamalı derslerde Endüstri Meslek Lisesi (16 Kişi \%28,1) ve Düz Lise (39 Kişi - \%21,3) mezunlarının başarı düzeylerinin daha düşük olduğu saptanmıştır. İlgili alternatif hipotez (H2) kapsamında yapılan Ki-Kare testi sonuçlarına göre; $\mathrm{P}<0,05 \quad(0,000)$ olarak bulunmuştur. Dolayısıyla alternatif hipotez $(\mathrm{H} 2)$ kabul edilerek $\mathrm{H} 0$ reddedilmiştir. Gelinen lisenin, Grafik Tasarım programında görülen uygulamalı derslerdeki başarısı üzerinde etkisi bulunmaktadır.

Grafik Tasarım programında alınan teorik derslerin başarısı üzerinde, gelinen lise türünün etkisi de incelenmiştir. Teorik ders olarak; Sanat Tarihi ve Baskı Teknikleri dersleri kullanılmıştır (Tablo 3).

Teorik dersler genel olarak değerlendirildiğinde öğrencilerin başarı oranı $(204$ Kişi - \%42,8) yüksek olduğu saptanmıştır. Lise türlerine göre bakıldığında, en başaralı lise türü 21 kişi $(\% 11,5)$ ile Düz lise olurken, ikinci sırada 10 kişi $(\% 8,7)$ ile Meslek Lisesi gelmektedir. Başarı oranının en düşük olduğu lise türü ise 33 kişi $(\% 57,9)$ ile Endüstri Meslek Lisesi olmuştur. İlgili alternatif hipotez (H3) kapsamında yapılan Ki-Kare testi sonuçlarına göre; P $>0,05 \quad(0,248)$ olarak bulunmuştur. Dolayısıyla alternatif hipotez (H3) reddedilmiştir. Gelinen lise türünün, Grafik Tasarım programında alınan teorik dersler üzerinde etkisi olmadığ sonucu ortaya çıkmıştır.

Araştırma kapsamında verileri kullanılan Grafik Tasarım programı mezunlarının, programda okudukları dönemlerde aldıkları uygulamalı dersler ile teorik derslerin başarılarının, birbirleri üzerinde etkisi olup olmadığına dair hipotezler oluşturulmuştur.

Tablo 4'te, program mezunlarının aldıkları "Sanat Tarihi" dersindeki başarının uygulamaları derslerdeki başarı ile ilişkili durumunu ile ilgili veriler yer almaktadır. Hem "Sanat Tarihi” dersi, hem de Uygulamalı derslerdeki başarı puanları 5 gruba ayrılmıştır. 
Tablo 1. Mezun Olunan Lisenin Önlisans Mezuniyet Derecesi Üzerindeki Etkisi

\begin{tabular}{|c|c|c|c|c|c|c|c|c|c|c|c|c|c|}
\hline & \multicolumn{10}{|c|}{ MYO Mezuniyet Derecesi } & \multirow{3}{*}{ SONUÇ } & \multicolumn{2}{|c|}{ Ki Kare } \\
\hline & \multicolumn{2}{|c|}{$2,00-2,50$} & \multicolumn{2}{|c|}{$2,51-3,00$} & \multicolumn{2}{|c|}{$3,01-3,50$} & \multicolumn{2}{|c|}{$3,51-4,00$} & \multicolumn{2}{|c|}{ Toplam } & & $\mathrm{K}^{2}$ & $\mathrm{P}$ \\
\hline Lise Türü & $\mathrm{N}$ & $\%$ & $\mathrm{~N}$ & $\%$ & $\mathrm{~N}$ & $\%$ & $\mathrm{~N}$ & $\%$ & $\mathrm{~N}$ & $\%$ & & \multirow{6}{*}{35,942} & \multirow{6}{*}{$\begin{array}{l}<0,05 \\
(0,000)\end{array}$} \\
\hline End. ML & 31 & 54,4 & 15 & 26,3 & 8 & 14,0 & 3 & 5,3 & 57 & 100 & \multirow{5}{*}{ KABUL } & & \\
\hline K. Mes. & 25 & 20,5 & 43 & 35,2 & 44 & 36,1 & 10 & 8,2 & 122 & 100 & & & \\
\hline Meslek & 18 & 15,7 & 47 & 40,9 & 36 & 31,3 & 14 & 12,2 & 115 & 100 & & & \\
\hline Düz & 47 & 25,7 & 70 & 38,3 & 51 & 27,9 & 15 & 8,2 & 183 & 100 & & & \\
\hline Toplam & 121 & 25,4 & 175 & 36,7 & 139 & 29,1 & 42 & 8,8 & 477 & 100 & & & \\
\hline
\end{tabular}

Tablo 2. Mezun Olunan Lisenin Uygulamalı Derslerdeki Başarı Üzerindeki Etkisi

\begin{tabular}{|c|c|c|c|c|c|c|c|c|c|c|c|c|c|c|c|}
\hline \multirow[b]{3}{*}{ Lise Türü } & \multicolumn{12}{|c|}{ UYGULAMALI DERSLER BAŞARI NOTLARI } & \multirow{3}{*}{ SONUÇ } & \multicolumn{2}{|c|}{ Ki Kare } \\
\hline & \multicolumn{2}{|c|}{$50-60$} & \multicolumn{2}{|c|}{$61-70$} & \multicolumn{2}{|c|}{$71-80$} & \multicolumn{2}{|c|}{$81-90$} & \multicolumn{2}{|c|}{$91-100$} & \multicolumn{2}{|c|}{ Toplam } & & $\mathrm{K}^{2}$ & $\mathrm{P}$ \\
\hline & $\mathrm{N}$ & $\%$ & $\mathrm{~N}$ & $\%$ & $\mathrm{~N}$ & $\%$ & $\mathrm{~N}$ & $\%$ & $\mathrm{~N}$ & $\%$ & $\mathrm{~N}$ & $\%$ & & \multirow{6}{*}{42,60} & \multirow{6}{*}{$\begin{array}{l}<0,05 \\
(0,000)\end{array}$} \\
\hline End. ML & 16 & 28,1 & 16 & 28,1 & 14 & 24,6 & 7 & 12,3 & 4 & 7,0 & 57 & 100 & \multirow{5}{*}{ KABUL } & & \\
\hline K. Mes. & 10 & 8,2 & 18 & 14,8 & 26 & 21,3 & 41 & 33,6 & 27 & 22,1 & 122 & 100 & & & \\
\hline Meslek & 7 & 6,1 & 21 & 18,3 & 28 & 24,3 & 36 & 31,3 & 23 & 20,0 & 115 & 100 & & & \\
\hline Düz & 39 & 21,3 & 41 & 22,4 & 38 & 20,8 & 42 & 23,0 & 23 & 12,6 & 183 & 100 & & & \\
\hline Toplam & 72 & 15,1 & 96 & 20,1 & 106 & 22,2 & 126 & 26,4 & 77 & 16,1 & 477 & 100 & & & \\
\hline
\end{tabular}

Tablo 3. Mezun Olunan Lisenin Teorik Derslerdeki Başarı Üzerindeki Etkisi

\begin{tabular}{|c|c|c|c|c|c|c|c|c|c|c|c|c|c|c|c|}
\hline \multirow[b]{3}{*}{ Lise Türü } & \multicolumn{12}{|c|}{ TEORİK DERSLER BAŞARI NOTLARI } & \multirow{3}{*}{ SONUÇ } & \multicolumn{2}{|c|}{ Ki Kare } \\
\hline & \multicolumn{2}{|c|}{$50-60$} & \multicolumn{2}{|c|}{$61-70$} & \multicolumn{2}{|c|}{$71-80$} & \multicolumn{2}{|c|}{$81-90$} & \multicolumn{2}{|c|}{$91-100$} & \multicolumn{2}{|c|}{ Toplam } & & $\mathrm{K}^{2}$ & $\mathrm{P}$ \\
\hline & $\mathrm{N}$ & $\%$ & $\mathrm{~N}$ & $\%$ & $\mathrm{~N}$ & $\%$ & $\mathrm{~N}$ & $\%$ & $\mathrm{~N}$ & $\%$ & $\mathrm{~N}$ & $\%$ & & \multirow{6}{*}{14,87} & \multirow{6}{*}{$\begin{array}{l}>0,05 \\
(0,248)\end{array}$} \\
\hline End. ML & 33 & 57,9 & 9 & 15,8 & 7 & 12,3 & 6 & 10,5 & 2 & 3,2 & 57 & 100 & \multirow{5}{*}{ RED } & & \\
\hline K. Mes. & 49 & 40,2 & 24 & 19,7 & 29 & 23,8 & 11 & 9,0 & 9 & 7,4 & 122 & 100 & & & \\
\hline Meslek & 53 & 46,1 & 16 & 13,9 & 23 & 20,0 & 13 & 11,3 & 10 & 8,7 & 115 & 100 & & & \\
\hline Düz & 69 & 37,7 & 37 & 20,2 & 31 & 16,9 & 25 & 13,7 & 21 & 11,5 & 183 & 100 & & & \\
\hline Toplam & 204 & 42,8 & 86 & 18,0 & 90 & 18,9 & 55 & 11,5 & 42 & 8,8 & 477 & 100 & & & \\
\hline
\end{tabular}

Tablo 4. Renk Bilgisi Dersi Başarısının Uygulamalı Derslerin Başarısı Üzerindeki Etkisi

\begin{tabular}{|c|c|c|c|c|c|c|c|c|c|c|c|c|c|c|c|}
\hline \multirow{3}{*}{$\begin{array}{l}\text { Sanat } \\
\text { Tarihi }\end{array}$} & \multicolumn{12}{|c|}{ UYGULAMALI DERSLER BAŞARI NOTLARI } & \multirow{2}{*}{ SONUÇ } & \multicolumn{2}{|c|}{ Ki Kare } \\
\hline & \multicolumn{2}{|c|}{$50-60$} & \multicolumn{2}{|c|}{$61-70$} & \multicolumn{2}{|c|}{$71-80$} & \multicolumn{2}{|c|}{$81-90$} & \multicolumn{2}{|c|}{$91-100$} & \multicolumn{2}{|c|}{ Toplam } & & $\mathrm{K}^{2}$ & $\mathrm{P}$ \\
\hline & $\mathrm{N}$ & $\%$ & $\mathrm{~N}$ & $\%$ & $\mathrm{~N}$ & $\%$ & $\mathrm{~N}$ & $\%$ & $\mathrm{~N}$ & $\%$ & $\mathrm{~N}$ & $\%$ & \multirow{6}{*}{ KABUL } & \multirow{6}{*}{70,55} & \multirow{6}{*}{$\begin{array}{c}<0,05 \\
(0,000)\end{array}$} \\
\hline $50-60$ & 45 & 23,8 & 48 & 25,4 & 47 & 24,9 & 37 & 19,6 & 12 & 6,3 & 189 & 100 & & & \\
\hline $61-70$ & 7 & 12,1 & 16 & 27,8 & 13 & 22,4 & 15 & 25,9 & 7 & 12,1 & 58 & 100 & & & \\
\hline $71-80$ & 8 & 9,8 & 19 & 23,2 & 18 & 22,0 & 23 & 28,0 & 14 & 17,1 & 82 & 100 & & & \\
\hline $81-90$ & 6 & 9,7 & 8 & 12,9 & 12 & 19,4 & 21 & 33,9 & 14 & 24,2 & 62 & 100 & & & \\
\hline $91-100$ & 6 & 7,0 & 5 & 5,8 & 16 & 18,6 & 30 & 34,9 & 29 & 33,7 & 86 & 100 & & & \\
\hline
\end{tabular}

Tablo 5. Baskı Teknikleri Dersinin Başarısının Uygulamalı Derslerin Başarısı Üzerindeki Etkisi

\begin{tabular}{|c|c|c|c|c|c|c|c|c|c|c|c|c|c|c|c|}
\hline \multirow{3}{*}{$\begin{array}{l}\text { Bask1 } \\
\text { Teknikleri }\end{array}$} & \multicolumn{12}{|c|}{ UYGULAMALI DERSLER BAŞARI NOTLARI } & \multirow{3}{*}{ SONUÇ } & \multicolumn{2}{|c|}{ Ki Kare } \\
\hline & \multicolumn{2}{|c|}{$50-60$} & \multicolumn{2}{|c|}{$61-70$} & \multicolumn{2}{|c|}{$71-80$} & \multicolumn{2}{|c|}{$81-90$} & \multicolumn{2}{|c|}{$91-100$} & \multicolumn{2}{|c|}{ Toplam } & & $\mathrm{K}^{2}$ & $\mathrm{P}$ \\
\hline & $\mathrm{N}$ & $\%$ & $\mathrm{~N}$ & $\%$ & $\mathrm{~N}$ & $\%$ & $\mathrm{~N}$ & $\%$ & $\mathrm{~N}$ & $\%$ & $\mathrm{~N}$ & $\%$ & & \multirow{6}{*}{107,44} & \multirow{6}{*}{$\begin{array}{l}<0,05 \\
(0,000)\end{array}$} \\
\hline $50-60$ & 50 & 23,7 & 62 & 29,4 & 53 & 25,1 & 36 & 17,1 & 10 & 4,7 & 211 & 100 & \multirow{5}{*}{ KABUL } & & \\
\hline $61-70$ & 10 & 15,2 & 13 & 19,7 & 15 & 22,7 & 18 & 27,3 & 10 & 15,2 & 66 & 100 & & & \\
\hline $71-80$ & 7 & 11,9 & 9 & 15,3 & 12 & 20,3 & 21 & 35,6 & 10 & 16,9 & 59 & 100 & & & \\
\hline $81-90$ & 1 & 2,2 & 6 & 13,0 & 13 & 28,3 & 13 & 28,3 & 13 & 28,3 & 46 & 100 & & & \\
\hline $91-100$ & 4 & 4,2 & 6 & 6,3 & 13 & 13,7 & 38 & 40,0 & 34 & 35,8 & 95 & 100 & & & \\
\hline
\end{tabular}

Tablo 6. Öğrenim Türünün Uygulamalı Derslerdeki Başarı Üzerindeki Etkisi

\begin{tabular}{|c|c|c|c|c|c|c|c|c|c|c|c|c|c|c|c|}
\hline \multirow{3}{*}{$\begin{array}{l}\text { Öğrenim } \\
\text { Türü }\end{array}$} & \multicolumn{12}{|c|}{ UYGULAMALI DERSLER BAŞARI NOTLARI } & \multirow{3}{*}{ SONUÇ } & \multicolumn{2}{|c|}{ Ki Kare } \\
\hline & \multicolumn{2}{|c|}{$50-60$} & \multicolumn{2}{|c|}{$61-70$} & \multicolumn{2}{|c|}{$71-80$} & \multicolumn{2}{|c|}{$81-90$} & \multicolumn{2}{|c|}{$91-100$} & \multicolumn{2}{|c|}{ Toplam } & & $\mathrm{K}^{2}$ & $\mathrm{P}$ \\
\hline & $\mathrm{N}$ & $\%$ & $\mathrm{~N}$ & $\%$ & $\mathrm{~N}$ & $\%$ & $\mathrm{~N}$ & $\%$ & $\mathrm{~N}$ & $\%$ & $\mathrm{~N}$ & $\%$ & & \multirow{4}{*}{3,041} & \multirow{4}{*}{$\begin{array}{l}>0,05 \\
(0,551)\end{array}$} \\
\hline Örgün & 45 & 15,0 & 57 & 18,9 & 63 & 20,9 & 82 & 27,2 & 54 & 17,9 & 301 & 100 & \multirow{3}{*}{ RED } & & \\
\hline II. Öğretim & 27 & 15,3 & 39 & 22,2 & 43 & 24,4 & 44 & 25,0 & 23 & 13,1 & 176 & 100 & & & \\
\hline Toplam & 72 & 15,1 & 96 & 20,1 & 106 & 22,2 & 126 & 26,4 & 77 & 16,1 & 477 & 100 & & & \\
\hline
\end{tabular}


Tablo 4 incelendiğinde; program mezunlarının "Sanat Tarihi" dersinden aldıkları başarı notlarının not grupları arasında orantılı dağıldığı görülmektedir. Bununla birlikte Uygulamalı derslerden başarılı olan öğrencilerin, Sanat Tarihi dersinden de başarılı olma oranı \%33,7 (29 Kişi) olmuştur. Öte yandan Uygulamaları derslerde düşük başarı elde eden öğrencilerin, Sanat Tarihi dersinden de düşük başarı oranına (45 Kişi - \%23,8) sahip olduğu tespit edilmiştir. İlgili alternatif hipotez (H4) kapsamında yapılan Ki-Kare testi sonuçlarına göre; $\mathrm{P}<0,05 \quad(0,000)$ olarak bulunmuştur. Dolayısıyla alternatif hipotez (H4) kabul edilerek, H0 reddedilmiştir. Ortaya çıkan sonuca göre; "Sanat Tarihi”" dersindeki başarı durumu ile uygulamaları derslerdeki başarı durumu arasında bir ilişki vardır. Bir dersteki başarı durumu diğer dersi etkilemektedir.

Araştırma kapsamında "Baskı Teknikleri" dersinin uygulamalı derslerdeki başarı üzerindeki etkisi araştırılmıştır. "Baskı Teknikleri" dersi ve uygulamalı derslerden alınan puanlar 5 gruba ayrılmıştır. Konuyla ilgili veriler Tablo 5'de yer almaktadır.

İlgili tabloya göre; program mezunlarının "Baskı Teknikleri" dersinden 91-100 puan arası puan alan mezunlar ile uygulamalı derslerinde aynı puan aralığında puan alanların oranına bakıldığında, mezunların \%35,8'i (34 Kişi) hem uygulamalı derslerde hem de "Baskı Teknikleri" dersinde aynı puan aralığındadır. Her iki derste de 50-60 puan aralığındaki mezun oranı ise \%23,7 (50 Kişi) olmuştur. Uygulamalı derslerde 50-60 aralığında puan alan mezunların, "Baskı Teknikleri" dersinden 91-100 aralığında puan alma oranı ise $\% 4,2$ (4 Kişi) düzeyindedir. İlgili alternatif hipotez (H5) kapsamında yapılan Ki-Kare testi sonuçlarına göre; $\mathrm{P}<0,05 \quad(0,000)$ olarak bulunmuştur. Dolayısıyla alternatif hipotez (H5) kabul edilirken, H0 reddedilmiştir. "Baskı Teknikleri" dersindeki başarı durumunun uygulamalı derslerin başarı durumu üzerinde etkisi olduğu ortaya çıkmıştır.

Araştırma kapsamında yer verilen bir diğer grup hipotez ise öğrenim türünün (örgün ve ikinci öğretim) derslerdeki (uygulamalı ve teorik) başarının ve mezuniyet not ortalaması üzerinde etkisi hakkında oluşturulmuştur. Bu bağlamda, uygulamalı derslerdeki başarı durumu ile program mezunlarının eğitim gördükleri öğrenim türü arasındaki ilişkiye bakılmıştır. Konuyla ilgili veriler Tablo 6'da yer almaktadir.

Tablo 6 incelendiğinde; programdan mezun olan öğrencilerin 301'i (\%17,9) örgün eğitim mezunuyken, 176's1 $(\% 13,1)$ II. öğretim mezunudur. Uygulamalı derslerde örgün öğretim öğrencilerinin \%17,9’u (54 Kişi) 91-100 arası bir puan alırken, II. öğretim öğrencileri için aynı not aralığındaki oran $\% 13,1$ 'dir (23 Kişi). Genel olarak değerlendirildiğinde ise mezunların en çok yoğunlaştığı oran \%26,4 (126 Kişi) ile 81-90 puan aralığında olmuştur. İlgili alternatif hipotez (H6) kapsamında yapılan Ki-Kare testi sonuçlarına göre; $\mathrm{P}>0,05 \quad(0,551)$ olarak bulunmuştur. Dolayısıyla alternatif hipotez (H6) reddedilerek H0 kabul edilmiştir. Mezunların öğrenim türünün (Örgün ya da II. Öğretim), görülen uygulamalı derslerin başarısı üzerinde etkisi yoktur.

Program mezunlarının öğrenim türlerinin, teorik dersler üzerindeki etkisi ile ilgili ortaya çıkan veriler Tablo 6'da yer almaktadır. Teorik dersler olarak, Sanat Tarihi ve Baskı Teknikleri derslerinin notları kullanılmıştır.

Tablo 7'ye bakıldığında; her iki öğrenim türünün de teorik derslerdeki başarı oranları oldukça düşüktür. Örgün (\%41,9 - 126 Kişi) ve II. öğretim (\%44,3 - 78 Kişi) mezunlarının 5060 puan aralığında yoğunlaştıkları görülmektedir. Öte yandan, 91-100 puan aralığına bakıldığında, örgün öğretimlerin \%9,3’ü (28 Kişi) ilgili puan aralığındayken, bu oran II. Öğretimler için \%8,0 (14 Kişi) olmuştur. İlgili alternatif hipotez $(\mathrm{H} 7)$ kapsamında yapılan Ki-Kare testi sonuçlarına göre; $\mathrm{P}>0,05 \quad(0,715)$ olarak bulunmuştur. Dolayısıyla alternatif hipotez (H7) reddedilerek H0 kabul edilmiştir. Mezunların öğrenim türünün (Örgün ya da II. Öğretim), görülen teorik derslerin başarısı üzerinde etkisi yoktur.

Araştırma kapsamında, mezunların, mezuniyet derecesi üzerinde öğrenim türünün etkisinin olup olmadığına dair değerlendirme yapılmıştır. Değerlendirme kapsamında, program mezuniyet derecesi 4 gruba ayrılmıştır. Konuyla ilgili veriler Tablo 8'de yer almaktadır.

Tablo 7. Öğrenim Türünün Teorik Derslerdeki Başarı Üzerindeki Etkisi

\begin{tabular}{|c|c|c|c|c|c|c|c|c|c|c|c|c|c|c|c|}
\hline \multirow{3}{*}{ Öğrenim Türü } & \multicolumn{12}{|c|}{ TEORİK DERSLER BAŞARI NOTLARI } & \multirow{3}{*}{ SONUÇ } & \multicolumn{2}{|c|}{ Ki Kare } \\
\hline & \multicolumn{2}{|c|}{$50-60$} & \multicolumn{2}{|c|}{$61-70$} & \multicolumn{2}{|c|}{$71-80$} & \multicolumn{2}{|c|}{$81-90$} & \multicolumn{2}{|c|}{$91-100$} & \multicolumn{2}{|c|}{ Toplam } & & $\mathrm{K}^{2}$ & $\mathrm{P}$ \\
\hline & $\mathrm{N}$ & $\%$ & $\mathrm{~N}$ & $\%$ & $\mathrm{~N}$ & $\%$ & $\mathrm{~N}$ & $\%$ & $\mathrm{~N}$ & $\%$ & $\mathrm{~N}$ & $\%$ & & \multirow{4}{*}{2,112} & \multirow{4}{*}{$\begin{array}{c}>0,05 \\
(0,715)\end{array}$} \\
\hline Örgün & 126 & 41,9 & 52 & 17,3 & 56 & 18,6 & 39 & 13,0 & 28 & 9,3 & 301 & 100 & \multirow{3}{*}{ KABUL } & & \\
\hline II. Öğretim & 78 & 44,3 & 34 & 19,3 & 34 & 19,3 & 16 & 9,1 & 14 & 8,0 & 176 & 100 & & & \\
\hline Toplam & 204 & 42,8 & 86 & 18,0 & 90 & 18,9 & 55 & 11,5 & 42 & 8,8 & 477 & 100 & & & \\
\hline
\end{tabular}

Tablo 8. Öğrenim Türünün Mezuniyet Not Ortalaması Üzerindeki Etkisi

\begin{tabular}{|c|c|c|c|c|c|c|c|c|c|c|c|c|c|}
\hline \multirow[b]{3}{*}{ Öğrenim Türü } & \multicolumn{10}{|c|}{ MYO Mezuniyet Derecesi } & \multirow{3}{*}{ SONUÇ } & \multicolumn{2}{|c|}{ Ki Kare } \\
\hline & \multicolumn{2}{|c|}{$2,00-2,50$} & \multicolumn{2}{|c|}{$2,51-3,00$} & \multicolumn{2}{|c|}{$3,01-3,50$} & \multicolumn{2}{|c|}{$3,51-4,00$} & \multicolumn{2}{|c|}{ Toplam } & & $\mathrm{K}^{2}$ & $\mathrm{P}$ \\
\hline & $\mathrm{N}$ & $\%$ & $\mathrm{~N}$ & $\%$ & $\mathrm{~N}$ & $\%$ & $\mathrm{~N}$ & $\%$ & $\mathrm{~N}$ & $\%$ & & \multirow{4}{*}{0,684} & \multirow{4}{*}{$\begin{array}{c}>0,05 \\
(0,877)\end{array}$} \\
\hline Örgün & 76 & 25,2 & 107 & 35,5 & 90 & 29,9 & 28 & 9,3 & 301 & 100 & \multirow{3}{*}{ RED } & & \\
\hline II.Öğretim & 45 & 25,6 & 68 & 38,6 & 49 & 27,8 & 14 & 8,0 & 176 & 100 & & & \\
\hline Toplam & 121 & 25,4 & 175 & 36,7 & 139 & 29,1 & 42 & 8,8 & 477 & 100 & & & \\
\hline
\end{tabular}


Tablo 8'e göre; örgün öğretim mezunlarının \%35,5'i (107 Kişi) 2,51-3,00 arası bir puan alırken, II. Öğretim mezunları için aynı aralıktaki oran \%38,6 (68 Kişi) olmuştur. Bunun yanında mezunların toplamda \%36,7'si (175 Kişi) 2,51-3,00 aralığında bir derece ile mezun olmuşlardır. Öte yandan, öğrenim türlerine göre mezuniyet derecesinin dağılımına bakıldığında, her iki tür içinde benzer bir dağılım olduğu saptanmıştır. İlgili alternatif hipotez (H8) kapsamında yapılan Ki-Kare testi sonuçlarına göre; $\mathrm{P}>0,05 \quad(0,877)$ olarak bulunmuştur. Dolayısıyla alternatif hipotez (H8) reddedilerek H0 kabul edilmiştir. Mezunların öğrenim türünün (Örgün ya da II. Öğretim) mezuniyet derecesi üzerinde bir etkisi bulunmamaktadır.

\section{Sonuç ve Öneriler}

Yapılan ölçümler sonucunda; mezunların geldikleri lise türünün, okudukları Grafik Tasarım programındaki mezuniyet notları üzerinde etkisi bulunmaktadır. Öğrencilerin meslek lisesi ya da düz liseden gelme durumlarına göre program başarıları değişiklik göstermektedir. Meslek lisesinden gelen öğrencilerin mezuniyet notları daha yüksekken, düz lise çıkışlılar daha düşük not ortalamasına sahiptir. Bu durumun, programın uygulamalı ders yoğunluğunun fazla olmasından kaynaklandığı tahmin edilmektedir. Düz lise çıkışlı öğrencilerin de başarısını arttırmak için uygulamalı dersler yeniden revize edilmeli ve düz lise çıkışlı öğrenciler için de uygun hale getirilmelidir.

Lise türünün etkisi, uygulamalı derslerde de kendini göstermiştir. Meslek lisesi çıkışlı öğrencilerin, Grafik Tasarım programında görülen uygulamalı derslerdeki başarı oranları daha yüksek iken, düz lise çıkışlıların başarı oranı düşüktür. Uygulamalı dersleri yapısal olarak gözden geçirilerek heterojen öğrenci grubuna göre yeniden yapılandırılmalidir.

Lise türünün, teorik dersler üzerindeki etkisine bakıldığında ise lise türünün teorik derslerdeki başarı üzerinde bir etkisinin olmadığı ortaya çıkmıştır. Teorik derslerin tüm öğrenciler için uygun bir yapıda olduğunu söylemek mümkündür.

Teorik derslerin uygulamalı dersler üzerinde etkisi olduğu görülmüştür. Dolayısıyla teorik dersler ile uygulamalı dersler arasındaki ilişki kuvvetlendirilerek birbirlerini tamamlar hale getirilmesi gerektiği düşünülmektedir.

Öğrenim türü (Örgün ve II. Öğretim) ile öğrencilerin teorik ve uygulamalı derslerdeki başarıları üzerinde bir etkinin bulunmadığ 1 tespit edilmiştir. Dolayısıyla öğretim türü ile ilgili bir düzenleme ya da değişikliğin yapılmasının anlamlı olmadığını söylemek mümkündür.

\section{Kaynakça}

Bahşi, N. (2011). Meslek Yüksekokullarının Sorunları ve Yöneticilerinin Tutum ve Davranışları Üzerine Bir Araştırma. Ç. Ü. Sosyal Bilimler Enstitüsü Dergisi, 2, $165-178$

Balcı, S. (1995a). Meslek Yüksekokullarının Geliştirilmesi İçin Teklifler. Ankara Üniversitesi Çankırı Meslek Yüksekokulu Dergisi, 1, 1-5.
Balcı, S. (1995a). Türkiye’deki Meslek Yüksekokullarının Kuruluşu ve Gelişimi. Ankara Üniversitesi Çankırı Meslek Yüksekokulu Dergisi, 1, 11-17

Becer, E. (1993). Yaratıcılık ve Grafik Tasarım. Anadolu Sanat Dergisi, 1, 43-49.

Becer, E. (1999). Illetişim ve Grafik Tasarımı. Ankara: Dost Kitabevi.

Bedük, B. D. (1996). Meslek Yüksekokullarının Problemleri ve Yeniden Yapılandırılmasının Gerekliliği. 21. Yüzyıla Doğru Meslek Yüksekokullarının Yeniden Yapılandırılması Sempozyumu, Çankırı, 80-91.

Bektaş, D. (1992). Çă̆daş Grafik Tasarımın Gelişimi. İstanbul: Yapı Kredi Yayınları.

Çakır, Ş. (2015). Modern Resim Sanatı ve Grafik Tasarım İlişkisi. Yüksek Lisans Tezi. İstanbul: İstanbul Arel Üniversitesi.

Drucker, J., \& McVarish, E. (2013). Graphic Design History (2nd Edition). UK: Pearson.

Durmuş, B., Yurtkoru, E.S., \& Çinko, M. (2013). Sosyal Bilimlerde SPSS'le Veri Analizi. İstanbul: Beta Yayıncılık.

Ertosun, A. (2006). Türkiye'deki Grafik Sanat Eğitimi ile Amerika'daki Grafik Sanat Eğitiminin Karşılaştırılması. Yüksek Lisans Tezi. İzmir: Dokuz Eylül Üniversitesi.

Gombrich, E.H. (1980). Sanatın Öyküsü. (çev. B. Çömert) İstanbul: Remzi Kitabevi.

Henden, R. (2006). Üçüncü Yılında Sinavsız Geçiş Uygulamaları: Alaplı Melek Yüksekokulu Örneği. $Z K \ddot{U}$ Sosyal Bilimler Dergisi, 2(4), 157-168

Karasar, N. (1981). Önlisans Eğitimi ve Teknik Eğitimde Uygulanabilirliği - Tarama Modelinde Bir Araştırma. Ankara: Ankara Üniversitesi Basımevi.

Kavak, Y. (1998). Short-Cycle Higher Education: A Review of OECD Countries Experieces of Turkey. Hacettepe Üniversitesi Eğitim Fakültesi Dergisi, 14, 100-106.

Lynton, N. (2004). Modern Sanatın öyküsü. (çev. C. Çapan ve S. Öziş) İstanbul: Remzi Kitabevi.

Mercin, L., \& Alakuş, A.O. (2009). Sanat Eğitimi ve Görsel Sanatlar Öğretimi. Ankara: Pagema Yayıncılık

MSGSÜ (2011). Sanayi-i Nefise Mekteb-i Alisi Talimatnamesi. İstanbul: MSGÜ Sanayi-i Nefise Mektebi-i Yayınları Çeviri Dizisi 1.

Nargül, Ş., \& Yüksel, E. (2009). Meslek Yüksekokullarına Sınavsız Geçişte İzlenen kriterlerin Değerlendirilmesi. Abant İzzet Baysal Üniversitesi Dergisi, 9(2), 189-205.

Odabaşı, B. (2013). Mesleki ve Teknik Önlisans Programlarında Kalite Arayışı: Sınavsız Geçiş. Ç. $\ddot{U}$. Sosyal Bilimler Enstitüsü Dergisi, 2, 269-286.

Özdemir, A. (2009). Veri Tabanlarından Bilgi Keşfi İle Meslek Yüksekokullarında Sinavsız Geçişin Değerlendirilmesi. EKEV Akademi Dergisi, 13(40), 95104. 
Sevindik, O. (2016). Yükseköğretimde Grafik Tasarım Eğitimi ve Bir Model Önerisi. Sanatta Yeterlik Tezi. İstanbul: İstanbul Arel Üniversitesi.

Sözen, M., \& Tanyeli, U. (1992). Sanat Kavram ve Terimleri Sözlüğü. İstanbul: Remzi Kitapevi.

Sürmeli, K. (2013). Amerikan Grafik Tasarımında Avrupa Modernizmi. Fine Arts, 9(2), 101-110.

Tansuğ, S. (1993). Çağdaş Türk Sanatı. İstanbul: Remzi Kitabevi.

Tepecik, A. (1998). Hizmet Pazarlamasında Grafik Sanatların Yeri ve Önemi. Konfeksiyon Teknik Dergisi, (52), 65-71.

Tunç, A. (2005). Yüksekokullarına Sınavsız Geçişin Değerlendirilmesi. ZKÜ Sosyal Bilimler Dergisi, 1(2), 75-81.

Vardar, Y. (1971). Yüksek Öğretimde Önlisans Sorunu. İzmir: Ege Üniversitesi Matbaası.

YÖK (2006a). Meslek Yüksekokullarl: Mevcut Durum ve Öngörüler. Ankara: Yükseköğretim Kurumu Yayınları.

YÖK (2006b). Meslek Yüksekokullarının Bugünkü Durumu ve Mesleki ve Teknik Ortaögretim Okullarından Melek Yüksekokullarına Sinavsız Geçişin Değerlendirilmesi. Ankara: Yükseköğretim Kurumu Yayınları.

YÖK (2011). Türkiye Yükseköğretim Yeterlilikler Çerçevesi (TYYÇ) Temel Alan Yeterlilikleri Sanat Temel Alanı Raporu. Ankara: YÖK Yayınları. (Erişim: 01.08.2016), http://www.tyyc.sakarya.edu.tr/raporlar/21_SANAT_13 _01_2011.pdf

YÖK (2016). Yükseköğretim Bilgi Yönetim Sistemi. (Erișim: 13.09.2016), https://istatistik.yok.gov.tr/ 